\title{
Presentation of Howland Award to Waldo E. Nelson
}

\author{
Angelo M. DiGeorge ${ }^{[2]}$ \\ Temple University, St. Christopher's Hospital for Children, Philadelphia, Pennsylvania, USA
}

Reared in the Protestant ethic of discipline, diligence, and austerity, an analloyed pure Midwestern man of Churchillian drive and energy, Waldo Emerson Nelson is one of the great statesmen of modern American pediatrics. His Textbook of Pediatrics would qualify him for this award, but he has excelled in every area of pediatrics which has been favored by his touch.

It has been said that only great attributes make great people and Bill Nelson has many of them. His foibles and peccadillos, on which I shall not dwell excessively, are sufficiently numerous to have contributed significantly to the amusement of his staff and friends but have not been of a character to flaw his fabric of uncompromising determination and granite conviction of right and wrong. To those who don't know him well, he may appear austere and stern and his well known knack for tongue-in-cheek reproaches provide a facade of gruffness, but he is a warm and compassionate human being with a deep regard for the sensitivities of others. He has a keen sense of humor and is especially fond of acerbic jibes directed at himself.

The facts of his life are simple. Born in McClure, Ohio, 29 miles from Toledo, in 1898, he owes his given name to his grandmother, a devotee of the Unitarian minister turned lecturer and poet, Ralph Waldo Emerson. Of course, children are not fond of unusual names so he established his pecking order with his six brothers and the children who came to his father's drug store by insisting that they call him by the more conventional name of Bill, a name still preferred and the only one to which he responds-except for one occasion. While deep-sea fishing with a half-dozen members of his department he insisted that they call him "Bill" rather than "Doctor Nelson." About 10 minutes later, Arthur McElfresh, emboldened by this new-found permissiveness and by the conviviality of the occasion said, "Bill, pass me a beer." No response. Again, he repeated, "Bill, pass me a can of beer." Still no response. At this point, chagrined at his own temerity, Mac virtually whispered, "Doctor Nelson, pass me a beer." There was an immediate reaction. To this day when taunted about the episode, "Doctor Nelson" denies that it ever occurred.

After completing high school, he applied to and was accepted at The Wharton School of Finance where he intended to pursue a career in business. Lack of money forced him to defer those plans temporarily and he went to work as mail clerk and office boy for Mr. John Willys at the Willys-Overland plant in Toledo, Ohio. Had he continued with the company, Willys-Overland would probably be one of the top three today, and Toledo rather than Detroit might have become the automobile capital of the world.

In the Twenties salesmanship was considered the greatest of the performing arts and Bill Nelson worked at perfecting this art form through high school and college. He sold peaches and he sold insurance. He sold the Saturday Evening Post and the Country Gentleman and won a prize for selling the most Curtis Publications in Northern Ohio. He sold fender braces, which he ordered from a Chicago mail order house at 33 cents each. Before an unsuspecting car owner knew what was happening he would install one on his car and then ask for a dollar. He became steward at his fraternity house and got them out of a financial hole. Is it any wonder that in later years he endeared himself to Saunders and to Mosby when his book and his journal increased their profits. But above all he promoted the concept of the child as a whole individual long before the phrase "the new pediatrics" was coined.

In 1917 the country was at war and in the fall of that year he enlisted in the army. He was assigned to the Student Army Training Corps and after a circuitous route ended up back in Ohio at Wittenberg College. On the very first night on campus it was providential 
that he met another freshman named Marge Harris. Although this pair-bonding was inevitable, years intervened before they met again and married. Nelson's unabashed pride in Marge and in their three children, Jane, Ann, and Bill, is amply justified. Furthermore, he always made his hospital family feel as if they were a part of his own family.

1. hile at Wittenberg College his interests turned to medicine. After graduation from the University of Cincinnati School of Medicine in 1926, he interned at Cincinnati General Hospital and then spent 2 years of residency at the new Cincinnati Children's Hospital.

These formative years in Cincinnati shaped him into the distinctive mold which was to be his hallmark in later years, for he came under the preceptorship of A. Graeme Mitchell and he went on to become his righthand man. Mitchell had gone to Cincinnati from Philadelphia in 1924. In a few years he had built a new Children's Hospital and a Research Foundation and he coralled a full time staff of clinicians and investigators, each of whom was to become notable on the basis of his own accomplishments.

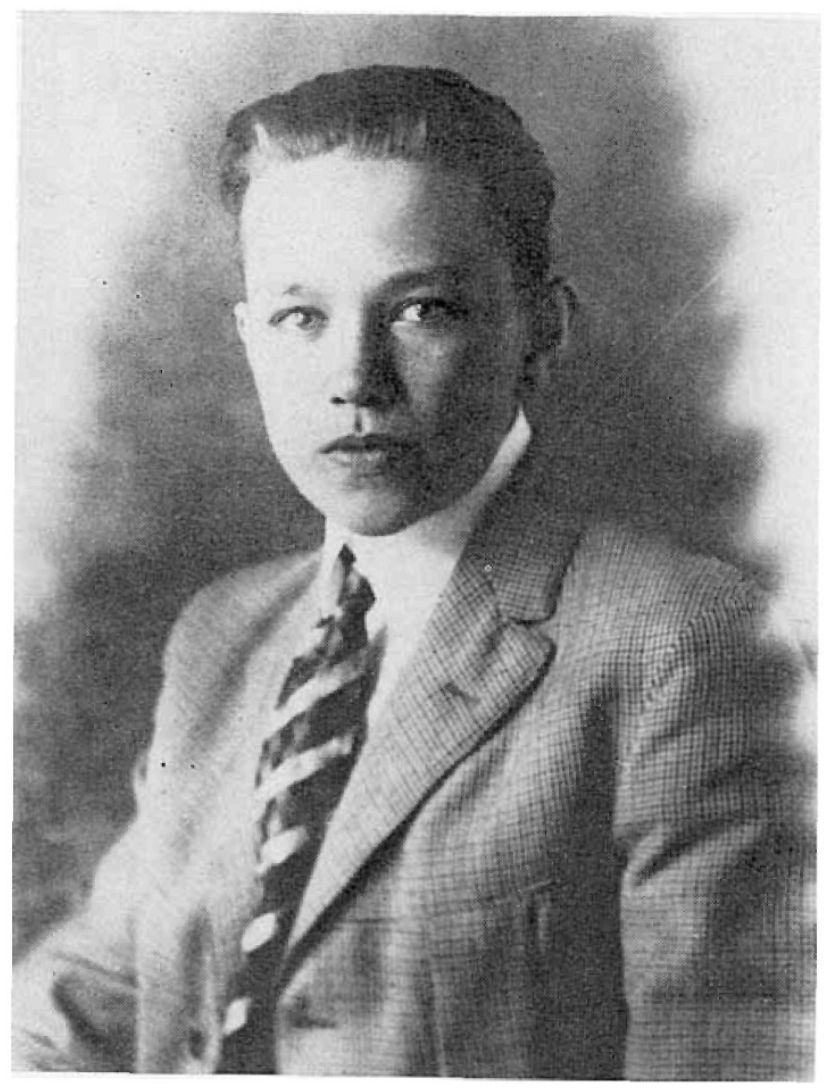

Fig. 1. The young boy in McClure, Ohio.

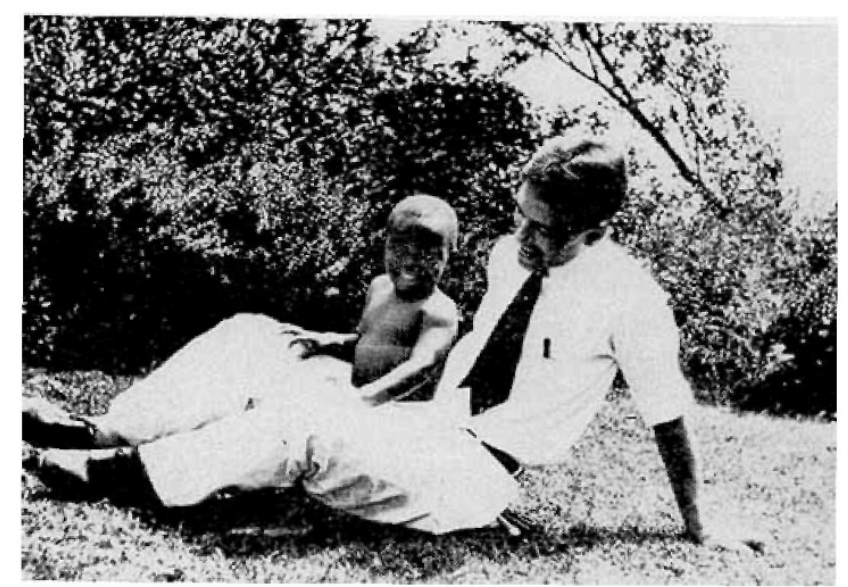

Fig. 2. As an intern at Cincinnati General Hospital.

These were exciting years, and Doctor Nelson played an active role in the development of one of the finest pediatric departments in the world, a setting in which patient care, teaching, and research were exquisitely integrated into a smoothly operating whole. This was a new model for all aspiring future chairmen, and the lessons learned there served him well in later years.

Each of the clinical staff carved out a niche of specialization for himself; Nelson's particular interests were tuberculosis, diabetes, and nephritis. He organized effective clinics for each and directed clinical research in these disorders. At the same time he became medical director of the children's convalescent home. His research contributions are a matter of record, but his skills as physician and counselor are best exemplified by the following account.

In those days there was in Cincinnati an active young boy, the son of a semiprofessional baseball pitcher, who aspired to a career with the Cincinnati Reds. At the age of 10 he developed diabetes. For a while, the greatest activity allowed him was playing marbles, since baseball and other forms of strenuous exercise were thought to be harmful and had been interdicted by his physicians. He then came under the care of Dr. Nelson and as Billy Talbert recounted years later, "luckily for me, my physician had 'liberal' ideas" about the mangement of diabetes. With Nelson's encouragement Bill Talbert took up tennis, went on to become Captain of the United States Davis Cup team for 5 successive years, and was subsequently elected into the Tennis Hall of Fame.

Although Nelson's management of Talbert at the time was considered radical, it has now become the standard and it aptly illustrates his aphorism that "one must look at the whole child and not just his blood sugar." 
In 1940, Dr. William N. Parkinson, Dean of Temple University School of Medicine, was looking for a Chairman of Pediatrics and he heard about this young man Nelson. Parky, a one-man search committee, decided to scout his candidate before offering him the job. He went to the pediatric meetings at Sky Top, where Dr. Nelson was presenting papers on the programs of both the Society for Pediatric Research and the American Pediatric Society. Parky listened to cne of the presentations; in later years he was fond of saying that it was the only good talk he had ever heard him give, undoubtedly a caustic commentary at Nelson's well known habit of hesitating in midsentence for painfully long periods while he searches for the precise word to express his thoughts. Although he had already turned down other offers because he had expected to go into research, he decided to accept the challenge of the chairmanship at Temple.

The spring following his move to Philadelphia, Mitchell telephoned him to tease him and in his usual jovial manner asked what he had done to merit his newly acquired membership in the American Pediatric Society. Unknown to Nelson until several days later was the fact that Mitchell had called from an oxygen tent and in a few days was dead.

After the death of both Griffith and Mitchell in 1941, A. M. Green, then Vice-President of the Saunders Company, asked Bill Nelson to take over the Griffith and Mitchell textbook. He accepted this awesome responsibility only after considerable reflection; through the next 30 years and six editions, the book has never been far from his conscious mind. A few years ago, while seemingly miles away from work in a cafe in Athens sipping Ouzo in the shadow of the Acropolis, he suddenly broke the idyllic mood and asked Dr. M arkany, "By the way Joe, when do I get your chapter for the book?" The fourth edition--the first over which Nelson had direction-sold six times as many copies as the third edition, and the total number of copies of the Nclsonedited textbook has broken virtually all records for medical texts. The book has been translated into Spanish, Italian, French, and Persian, and there is available in the Far East a special Asian edition, not to mention a pirated Taiwan edition. There is probably no medical outpost on earth where doctors treat children without a copy of the book at hand.

There are many anecdotes about the book. The best known is the "for the Birds, pp. 1-1413" entry in the index of the seventh edition [1]. But the story I like best revolves around Lawrence Saunders, publisher and incidently the owner of a stable of horses, who was giving a dinner during the course of an American Medical Association meeting in Atlantic City. Each of the distinguished authors present was asked to say a few words. $\mathrm{W}$ hen it came his turn to speak, Dr. Nelson rose in his characteristically deliberate manner and with measured cadence said, "It seems to me that I have spent a great deal of my life working weekends in order to feed Lawrence Saunders' horses." Saunders did not seem to think this was funny, but those who have been close to the book understand that this was no exaggeraticn.

Many admire the bock, or the Green Bible, as it is known to his students, but few are aware of the enormous effort, attention to detail, and tough scrutiny that Nelson himself injects into each edition. The book reads as though it were written by one person rather than by 78

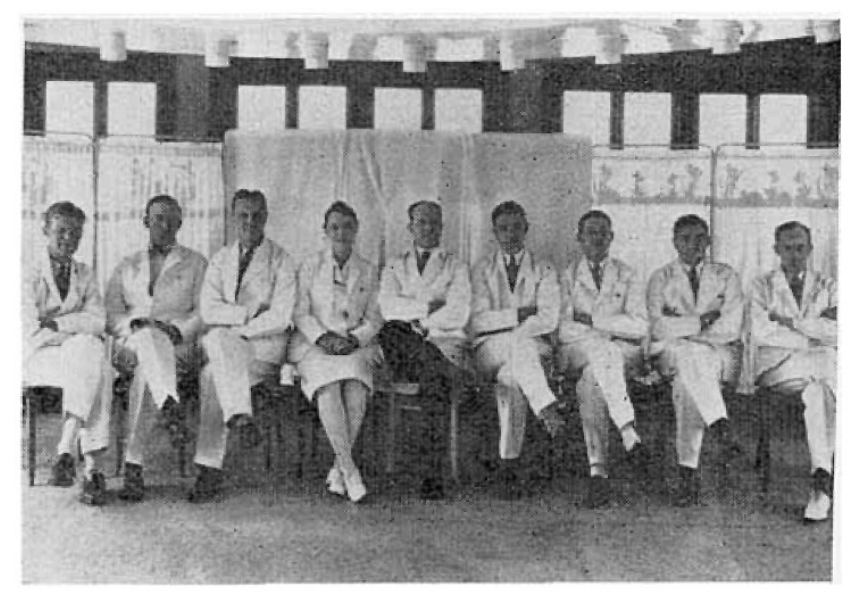

Fig. 3. Waldo E. Nelson as a resident (at immediate left of Dr. A. Graeme Mitchell) at Cincinnati Children's Hospital.

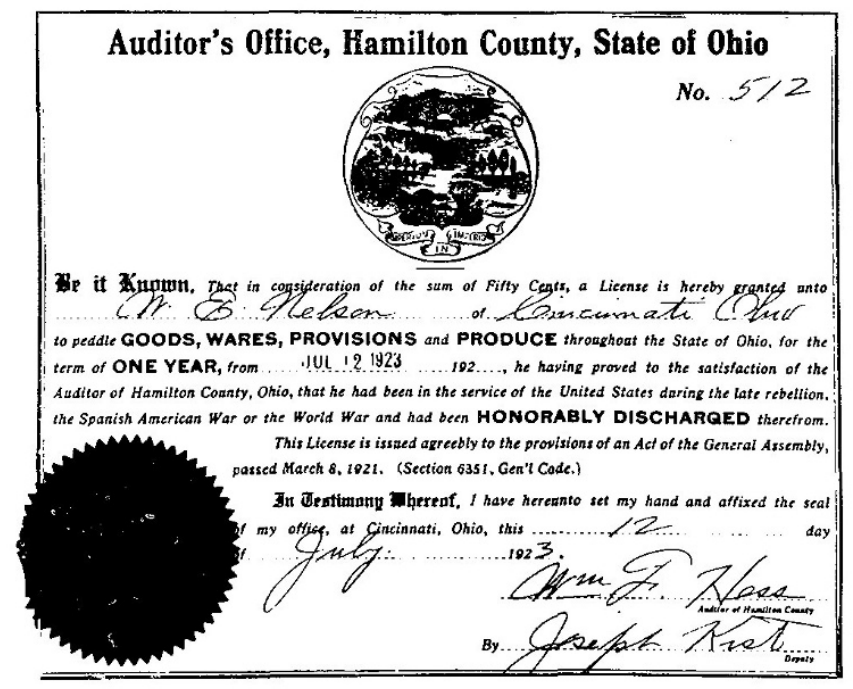

Fig. 4. Peddler's license issued to Dr. Nelson on July 12, 1923. 
contributors because the operation is a gigantic rewrite job for the editor. Any contributor who covets his every written word is frustrated by Nelson's editing for he buys red pencils by the dozens.

In the forties the department at Temple was small. He brought with him Dr. Nina Anderson, a neonatologist; John Bartram, who had just completed his residency; and Howard Robinson, an associate of Glen Cullen. With few facilities and a small budget, he concentrated on the teaching effort and by the students' own appraisal made pediatrics the most lively of the clinical arts. But the memories of Cincinnati lingered on, and his visions of pediatrics were still unfulfilled.

In 1947, the opportunity arose to affiliate the department of pediatrics with St. Christopher's Hospital for Children, a 100-bed community hospital about a mile from the medical school. Attended completely by visiting staff, one-half of admissions consisted of T's and A's and the other half of enteritides. As medical director of this hospital, Nelson was off and running. In a few years he relocated the department, built a new 150-bed hospital, established a core of investigators, and singlehandedly brought this community hospital into national light. All of this was accomplished by sheer determination and administrative ability, for there were no large benefactors like the Proctors in Cincinnati.

St. Christopher's Hospital for Children never had a

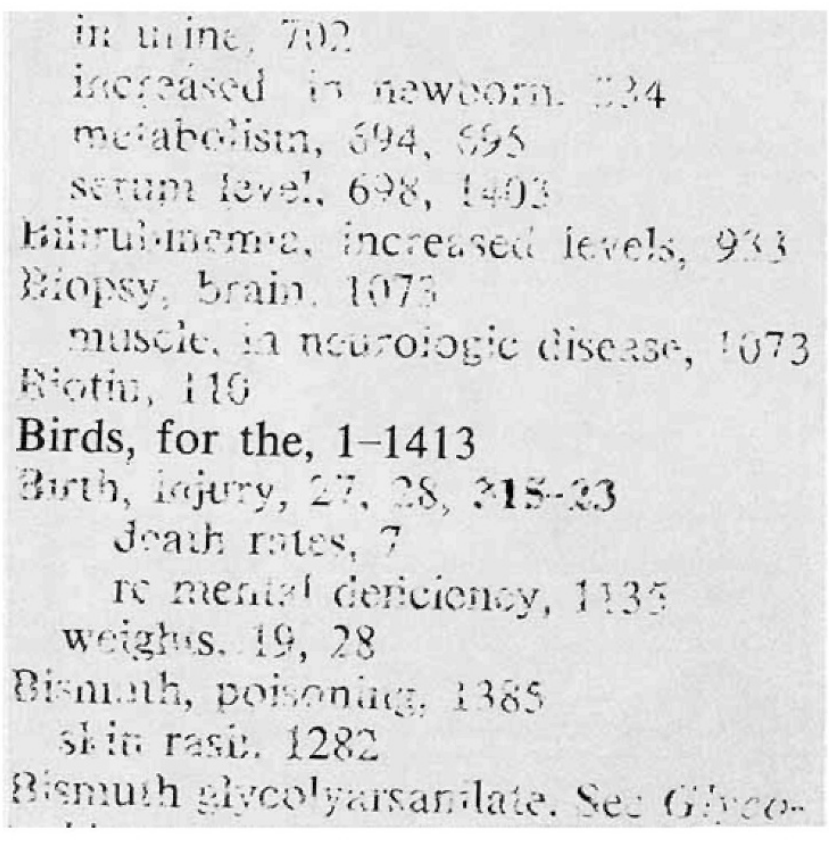

Fig. 5. Excerpt from index page of Seventh Edition of Nelson's Texlbook of Pediatrics [1].

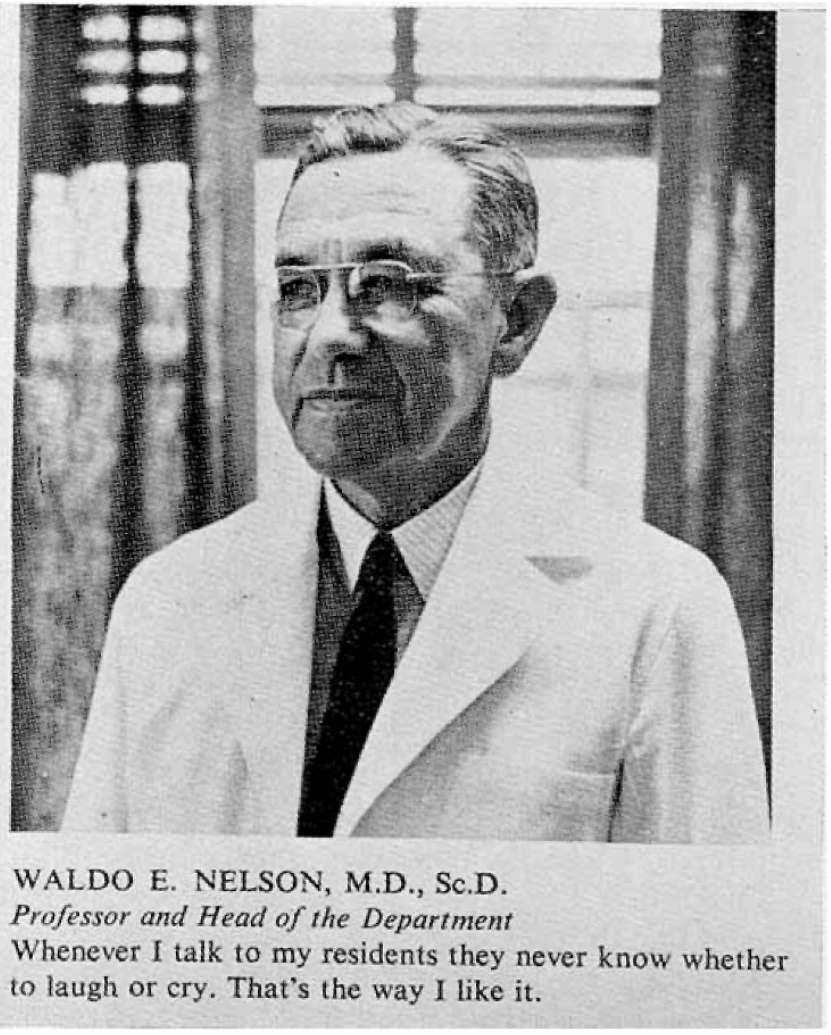

Fig. 6. As seen by medical students in 1961 yearbook, The Skull.

religious affiliation, but it did develop an ethos during Dr. Nelson's reign. To work for him was like joining a monastic order; one took vows of poverty, dedication, and self-denial. As a consequence the perceptive medical student's sobriquet for the hospital became St. W'aldo's. Honest and scrupulous to a fault, he considers it petty larceny to take home a pencil or pad from the office even for the purpose of using them for hospital work. Obsessed with fiscal responsibility, he deplores the practice of traveling first class when any but personal funds are being used. I vividly recall being sanctimoniously lectured at the San Francisco airport 2 years ago while we were waiting for our aircraft because I was flying first class at the expense of one of the pediatric journals while he was voluntaily flying economy class at the expense of his journal. However, he never asked more of anyone than he himself gave, and the enjoyment he has derived over the years from inculcating his staff and students in his values has far outweighed the pain of self-denial.

In 1959, Dr. Nelson assumed the Editorship of the Journal of Pediatrics. The previous year only 200 manuscripts had been submitted. During his 1st year as editor the number rose to 300 , but 84 of these he had literally 
solicited on the street. In the ensuing years the number of manuscripts submitted rose to over 850 , and his editorial genius resulted in a doubling of subscriptions. Earlier this year he sent a personal letter of appreciation to 379 reviewers and attributed to them the success of the journal. Virtually in the return mail he received over 50 letters of thanks from the reviewers for the opportunity of being associated with this venture.

It was only natural that such a dominant personality should have transmitted his traits to his students, with varying degrees of penetrance, of course. Many of his former residents have gone out to clone other departments of pediatrics and continue to perpetuate his finest attributes.

Since his retirement from the chairmanship in 1964, he has worked harder than ever, spending 50 to $60 \mathrm{hr}$ a week on the journal alone. But then everyone knowsfor he himself has said it - that he never takes vacations. We won't mention how during his spartan life he has managed to travel from the Land of the Lapps to Lake
Titicaca and from Tahiti to Turkey. Nor will we comment on his passion for golf since he has never achieved any prowess in this endeavour. I have it on good authority that when Dr. J. B. Bilderback was almost 100 years of age he defeated Nelson on the links. The highest achievement of his golfing career was the breathless game played at La Paz, Bolivia, a course 2 miles higher than his customary one at Valley Forge.

Mr. President, if this sketchy account of this remarkable man appears to have been a bit long, it is only because Dr. Nelson did not have an opportunity to edit it and reduce it to a 5-min presentation.

\section{Reference and Notes}

1. Nelson, W. E.: Textbook of Pediatrics, Ed. 7. (Saunders, Philadelphia, 1959).

2. Requests for reprints should be addressed to: A. M. DiGeorge, M.D., St. Christopher's Hospital for Children, 2600 N. Lawrence Street, Philadelphia, Pa. 19133 (USA).

3. Received for publication June 26, 1972. 